\title{
MATERNAL AND FOETAL OUTCOMES IN GESTATIONAL DIABETES MELLITUS
}

\author{
Manikant Singla1 , Ashish Ahuja², Sunil K. Juneja ${ }^{3}$ \\ ${ }^{1}$ Associate Professor, Department of Endocrinology, Dayanand Medical College \& Hospital, Ludhiana. \\ ${ }^{2}$ Associate Professor, Department of Surgery, Dayanand Medical College \& Hospital, Ludhiana. \\ 3Professor, Department of Obstetrics \& Gynaecology, Dayanand Medical College \& Hospital, Ludhiana.
}

ABSTRACT
BACKGROUND
The aim of the study was to evaluate maternal and foetal outcomes in pregnant females having gestational diabetes mellitus.
Gestational diabetes mellitus is defined as carbohydrate intolerance that begins or is first recognised during pregnancy. Many studies
suggest that early diagnosis and strict control of blood sugar levels throughout the pregnancy can significantly reduce maternal and
foetal complications.

\section{MATERIALS AND METHODS}

A retrospective study was done from January 2010 to December 2014 on 5400 pregnant patients delivered in Department of Obstetrics and Gynaecology in Dayanand Medical College and Hospital, Ludhiana.

\section{RESULTS}

The result of this study confirms that there is increased maternal and foetal morbidity in terms of preterm delivery, rate, neonatal complications and caesarean section.

\section{CONCLUSION}

GDM is a condition that should be treated aggressively and it is a problem that affects a significant number of women during pregnancy. Women with GDM are at an increased risk for adverse obstetric and perinatal outcomes.

\section{KEYWORDS}

Gestational, Diabetes Mellitus, Maternal, Foetal, Glucose, Outcomes.

HOW TO CITE THIS ARTICLE: Singla M, Ahuja A, Juneja SK. Maternal and foetal outcomes in gestational diabetes mellitus. J. Evolution Med. Dent. Sci. 2016;5(84):6239-6241, DOI: 10.14260/jemds/2016/1410

\section{BACKGROUND}

Gestational diabetes mellitus (GDM) is defined as carbohydrate intolerance that begins or is first recognised during pregnancy. ${ }^{1}$ Risk factors for gestational diabetes include diabetes in a first degree relative, history of glucose intolerance including previous gestational diabetes, marked obesity and a previous infant with macrosomia. ${ }^{2}$ Many studies suggest that early diagnosis and strict control of blood sugar levels throughout the pregnancy can significantly reduce maternal and foetal complications (Oman Medical Journal). Census has put forth a sequential model of testing using a $50 \mathrm{~g}$ non-fasting one hour glucose challenge test between 24 and 28 weeks gestation. In high risk pregnant women, screening with $50 \mathrm{~g}$ glucose GCT is done at mere first antenatal visit. ${ }^{3}$

Women with a positive screening test, the $100 \mathrm{~g} 3 \mathrm{hour}$ oral glucose tolerance test is used to diagnose gestational diabetes. WHO recommends simultaneous screening and diagnosis using a $75 \mathrm{~g}$ OGTT. 4

Medical nutritional therapy is the first line of treatment. Pharmacotherapy is indicated when medical nutritional therapy is associated with elevated fasting glucose levels, lack of expected weight gain or when patient is constantly hungry.

Financial or Other, Competing Interest: None.

Submission 18-07-2016, Peer Review 25-08-2016,

Acceptance 01-09-2016, Published 18-10-2016.

Corresponding Author:

Dr. Ashish Ahuja,

\#132/1, Rani Jhansi Road,

Civil Lines, Ludhiana.

E-mail:drahuja17@gmail.com

DOI: $10.14260 / \mathrm{jemds} / 2016 / 1410$
A retrospective study was done from January 2010 to December 2014 on 5400 pregnant patients delivered in Department of Obstetrics and Gynaecology in Dayanand Medical College and Hospital, Ludhiana. Out of 5400 women, 129 had Gestational diabetes mellitus. Maternal and foetal outcomes were studied in these pregnant women. The data was statistically analysed.

\section{AIM OF THE STUDY}

The aim of the study was to evaluate maternal and foetal outcomes in pregnant females having gestational diabetes mellitus.

\section{MATERIALS AND METHODS \\ Exclusion Criteria}

Women with diabetes mellitus co-existing with other medical conditions such as sickle cell disease.

\section{Inclusion Criteria}

Women with singleton pregnancy and gestational age between 24 to 28 weeks.

A retrospective study was done from January 2010 to December 2014 on 5400 pregnant patients delivered in Department of Obstetrics and Gynaecology in Dayanand Medical College and Hospital, Ludhiana. Out of 5400 women, 129 had gestational diabetes mellitus. Maternal and foetal outcomes were studied in these pregnant women. The data was statistically analysed.

\section{RESULTS}

\begin{tabular}{|c|c|}
\hline Total No. of Deliveries & 5400 \\
\hline Patients with DM & 129 \\
\hline Table 1
\end{tabular}


As shown in table 1, a total of 5400 deliveries were conducted between 2010 and 2014 . Out of the 5400 deliveries that were conducted, 129 had diabetes mellitus. The incidence of GDM were found to be $2.38 \%$.

\begin{tabular}{|c|c|}
\hline Age & Frequency \\
\hline$<25$ & 10 \\
\hline $25-30$ & 63 \\
\hline $31-35$ & 36 \\
\hline $36-40$ & 20 \\
\hline \multicolumn{2}{|c|}{ Table 2: Age wise Distribution } \\
\hline
\end{tabular}

As depicted in table 2, majority of the females were in the age group of 25-30 years. 63 females were in the age group of 25-30 years. The incidence was less in the age group less than 25 years. There were 36 females in the age group of 31 to 35 years and 20 females in the age group of 36 to 40 years.

\begin{tabular}{|l|c|}
\hline Caesarean & 77 \\
\hline Vaginal & 52 \\
\hline \multicolumn{2}{|c|}{ Table 3: Mode of Delivery } \\
\hline
\end{tabular}

Out of 129 deliveries, caesarean was the mode of delivery in 77 females and vaginal delivery was done in 52 females.

\begin{tabular}{|c|c|}
\hline Foetal Distress & 39 \\
\hline Obstructed Labour/Cephalopelvic Disproportion & 14 \\
\hline Antepartum Haemorrhage & 5 \\
\hline Failure of Induction & 8 \\
\hline Elective & 11 \\
\hline \multicolumn{2}{|c|}{ Table 4: Indications of Caesarean Section } \\
\hline
\end{tabular}

Out of the 129 cases of gestational diabetes mellitus, the indication for cesarean section was foetal distress in 39 cases, obstructed labour and cephalopelvic disproportion in 14 cases, antepartum haemorrhage in 5 cases, failure of induction in 8 cases and elective cesarean in 11 cases.

\begin{tabular}{|c|c|}
\hline $\begin{array}{c}\text { Pregnancy-induced Hypertension } \\
\text { (Gestational Hypertension ) }\end{array}$ & 23 \\
\hline Diabetes Ketoacidosis & 3 \\
\hline Vaginal Candidiasis & 19 \\
\hline Polyhydramnios & 17 \\
\hline Oligohydramnios & 6 \\
\hline Table 5: Associated Maternal Complications \\
\hline
\end{tabular}

As shown in table 5 , the associated maternal complications were pregnancy-induced hypertension in 23 cases, vaginal candidiasis in 19 cases, polyhydramnios in 17 cases, oligohydramnios in 6 cases and diabetic ketoacidosis in 3 cases.

\begin{tabular}{|c|c|c|}
\hline \multirow{2}{*}{ Intrapartum } & Intrauterine Growth Retardation & 17 \\
\cline { 2 - 3 } & Macrosomia & 8 \\
\hline Neonatal & Jaundice & 42 \\
\hline \multirow{6}{*}{} & Necrotising Enterocolitis & 1 \\
\cline { 2 - 3 } & Seizures & 2 \\
\cline { 2 - 3 } & Hypoglycaemia & 6 \\
\cline { 2 - 3 } & Respiratory Distress & 19 \\
\cline { 2 - 3 } & Table 6: Foetal Complications \\
\hline
\end{tabular}

Foetal complications during the intrapartum period were intrauterine growth retardation seen in 17 cases and macrosomia in 8 cases. In neonatal period, jaundice was seen in 42 cases, respiratory distress in 19 cases, hypoglycaemia in 6 cases, seizures in 2 cases and necrotising enterocolitis in one case.

\section{DISCUSSION}

Pregnancy is a diabetogenic state manifested by insulin resistance and hyperglycaemia. A total of 5400 women were studied during this time period out of which 129 had gestational diabetes mellitus.

In our study, majority (92.3\%) of the women were in the age group of 25 to 30 years. Only $7.7 \%$ women were $<25$ yrs. of age. Increasing maternal age was associated with higher frequency of diabetes mellitus which was in accordance with other studies,5,6 showing that carbohydrate tolerance deteriorates progressively with age especially in females.

Out of 129 females, 52 females underwent normal vaginal delivery and 77 underwent caesarean section. Almost $60 \%$ of women having GDM had caesarean delivery. There is a direct relationship between hyperglycaemia and foetal growth and increased risk of caesarean section. Similar results were seen in other studies.

Woon in his study reported $41.8 \%$ caesarean rate. Incidence of shoulder dystocia was $4.65 \%$ which was the reason for the caesarean section.

Several obstetric problems occurred in diabetic pregnancy, the frequency of which was directly related to the extent of control. Polyhydramnios was present in 17 patients making its incidence to be $13.17 \%$. Reported incidence is 3 $32 \%$ which is comparable to our study.7,8

The reported incidence of macrosomia is $25-40 \%$. In our study, macrosomia was present in 8 babies making its incidence to be $6.2 \%$. Maximum baby weight was $4.4 \mathrm{~kg} .{ }^{9}$ The incidence of macrosomic infants and its associated morbidity has been established in other studies too. ${ }^{10-13}$ In this study, the indication for Caesarean section in mothers with gestational diabetes were twice likely to be for big babies and obstructed labour than in the controls. This observation further explains the fact that macrosomia was a single complication from which many other complications arise.

Other associated maternal complications were gestational hypertension which was present in 23 women making its incidence to $27.32 \%$. Incidence of stillbirth, diabetic ketoacidosis and vaginal candidiasis was $14.7 \%, 3 \%, 27.32 \%$ respectively. Other studies reported similar incidences. ${ }^{11,12}$ The increased incidence of vaginal candidiasis in women with gestational diabetes observed in this study would be explained by the increased spill of sugar in urine, thus contaminating the genitalia leading to increased fungal infection. Secondly, diabetic state is generally associated with reduced immunity encouraging opportunistic infections to become prevalent. It is difficult to say whether HIV infection played a role since no HIV tests were carried out.

Preterm delivery was present in 11 patients (8.52\%). A study done in Lahore has shown that 15 (38\%) of diabetic women delivered preterm. ${ }^{13,14}$ Polyhydramnios could be the associated cause for preterm delivery.

Neonatal complications included neonatal jaundice, hypoglycaemia and respiratory distress. Neonatal jaundice was the most common neonatal complication as reported in 
other studies. Neonatal hypoglycaemia occurred in $10 \%$ neonates in our study as compared to $25 \%$ as reported in other studies. ${ }^{15}$

Respiratory distress developed in 19 babies as they were preterm and required surfactant. The Join clinic reported an incidence of $31 \%$ respiratory distress syndrome in infants of diabetic women declining to an average of $5.5 \%$ in the same clinic with better glycaemic control. 16,17

The result of this study confirms that there is increased maternal and foetal morbidity in terms of caesarean section rate, preterm delivery rate and other neonatal complications.

\section{CONCLUSION}

GDM is a condition that should be treated aggressively and it is a problem that affects a significant number of women during pregnancy. Women with GDM are at an increased risk for adverse obstetric and perinatal outcomes. Although eradication of GDM is impossible, we can definitely prevent its adverse effects on pregnancy outcome. Increasing age, BMI, weight, marital period and positive family history for diabetes are highly prone to gestational diabetes mellitus and those women have to be considered as high risk group. Strictly, controlling of blood sugar level definitely gives good outcomes of gestational diabetes pregnancy.

\section{REFERENCES}

1. American college of obstetricians and gynecologists committee on practice bulletins-obstetrics. ACOG practice bulletin. Clinical management guidelines for obstetriciangynecologists. Number 30, September 2001 (replaces technical bulletin number 200, December 1994). Gestational diabetes. Obstet Gynecol 2001;98(3):525-38.

2. Metzger BE, Coustan DR. Summary and recommendations of the fourth international workshop-conference on gestational diabetes mellitus. The organizing committee. Diabetes Care 1998;21(Suppl 2):B161-7.

3. Agarwal MM, Dhatt GS, Punnose J, et al. Gestational diabetes: fasting and postprandial glucose as first prenatal screening tests in a high-risk population. J Reprod Med 2007;52(4):299-305.

4. Buhling KJ, Elsner E, Wolf C, et al. No influence of high- and low-carbohydrate diet on the oral glucose tolerance test in pregnancy. Clin Biochem 2004;37(4):323-7.
5. Khan A, Jaffarey SN. Screening for gestational diabetes. Medical Channel 1997;3:8-12.

6. Randhawa MS, Moin S, Shoaib F. Diabetes mellitus during pregnancy: a study of fifty cases. Pakistan J Med Sci 2003;19(4):277-82.

7. Falls J, Millo L. Endocrine disorders of pregnancy. In: Bankowski BJ, Hearne AE, Lambrou NC, et al. eds. The Johns Hopkins manual of gynecology and obstetrics. $2^{\text {nd }}$ edn. Philadelphia: Lippincott Williams \& Wilkins 2002:162-75.

8. Jovanovic-Peterson L. Medical management of pregnancy complicated by diabetes. $2^{\text {nd }}$ edn. Alexandria, VA: American Diabetic Association 1995.

9. Usmani AT, Waheed N. Pregnancy complicated with diabetes: a one year experience. J Pak Institute Med Science 1995;6(1,2):342-5.

10. Sermer M, Naylor CD, Gare DJ, et al. Impact of increasing carbohydrate intolerance on maternal-fetal outcomes in 3637 women without gestational diabetes: the Toronto trihospital gestational diabetes project. $\mathrm{Am} J$ Obstet Gynecol 1995;173(1):146-156.

11. Diabetes control and complications trial research group. The effect of pregnancy on microvascular complications in the diabetes control and complications trial. Diabetes Care 2000;23(8):1084-91.

12. Roberts RN, Moohan JM, Foo RL, et al. Fetal outcome in mothers with impaired glucose tolerance in pregnancy. Diabet Med 1993;10(5):438-43.

13. Ferchiou M, Zhioua F, Hadhri N, et al. Predictive factors of macrosomia in diabetic pregnancies. Rev Fr Gynecol Obstet 1994;89(2):73-6.

14. Gillmer MDG, Hurley PA. Diabetes and endocrine disorders in pregnancy. In: Edmonds DK, ed. Dewhurst's textbook of obstetrics and gynaecology for postgraduates. $6^{\text {th }}$ edn. Oxford: Blackwell Science 1999:197-209.

15. Perveen N, Saeed M. Gestational diabetes and pregnancy outcome: experience at Shaikh Zayed hospital. Mother and Child 1996;34(3):83-8.

16. Gellis SS, Hsia DYY. The infant of diabetic mothers. Am J Dis Child 1959;97(1):1-41.

17. Kitzmiller JL, Cloherty JP, Younger MD. Diabetic pregnancy perinatal morbidity. Am J Obstet Gynaecol 1978;131(5): 560-80. 